doi

\title{
Learning Al-Islam and Kemuhammadiyahan by Using Blended Learning in the New Normal at MTs Muhammadiyah Lubuk Jambi
}

\author{
Tarsupon \\ Madrasah Tsanawiyah Muhammadiyah Lubuk Jambi, Kuansing Riau \\ tarsupon@gmail.com
}

ARTICLE INFO

Article History:

Received: June 20,

2021

Revised: July 29, 2021

Accepted: August 20,

2021

Published: October 31, 2021

*Corresponding

Author:

Name:Tarsupon

Email:tarsupon@gmail.

com

Phone/WA:+628238127

1379

Keyword

\section{ABSTRACT}

The implementation of learning in the new normal is not much different from learning during the Covid-19 pandemic, therefore it takes teacher creativity for successful learning implementation. The creativity of AlIslam and Kemuhammadiyahan teachers at MTs Muhammadiyah Lubuk Jambi is to use blended learning, therefore this research aims to reveal how the implementation of blended learning in AIK learning in the new normal. The study uses a qualitative approach, the data source consists of key informants and additional informants. Data collection techniques are observation, interviews and documentation studies. Data is analyzed using interactive techniques. The application of blended learning model in MTs Muhammadiyah Lubuk Jambi is done by combining online and offline. The obstacles faced by using blended learning are from the aspect of teachers, learners and facilities. Research recommendations require comprehensive training to realize teachers who have information technology capabilities.

Online; offline; learning; Covid-19; New Normal

\section{Abstrak}

Pelaksanaan pembelajaran pada masa new normal tidak jauh berbeda dengan pembelajaran saat pandemi Covid-19, oleh karenanya dibutuhkan kreativitas guru untuk kesuksesan pelaksanaan pembelajaran. Kreativitas guru Al-Islam dan Kemuhammadiyahan di MTs Muhammadiyah Lubuk Jambi ialah dengan menggunakan blended learning, oleh karenanya penelitian ini bertujuan untuk mengungkapkan bagaimana implementasi blended learning dalam pembelajaran AIK pada masa new normal. Penelitian ini menggunakan pendekatan kualitatif, sumber data terdiri dari key informan dan informan tambahan. Teknik pengumpulan data ialah observasi, wawancara dan studi dokumentasi. Data dianalisis dengan menggunakan teknik interaktif. Hasil penelitian ialah Penerapan model pembelajaran blended learning di MTs Muhammadiyah Lubuk Jambi dilakukan dengan menggabungkan online dan offline. Kendala yang dihadapi dengan menggunakan blended learning ialah dari aspek guru, peserta didik serta fasilitas. Rekomendasi penelitian ialah dibutuhkan pelatihan yang komprehensif untuk mewujudkan guru yang memiliki kemampuan teknologi informasi.

Kata Kunci Online; offline; pembelajaran; Covid-19; New Normal

Tarsupon. (2021). Learning Al-Islam and Kemuhammadiyahan by Using Blended Learning in the New Normal at MTs Muhammadiyah Lubuk Jambi. Ruhama :Islamic Education Journal, Vol. 4, (No. 2), pp. 145-158 DOI: https://doi.org/10.31869/ruhama.v4i2845 


\section{INTRODUCTION}

Seiring dengan orientasi pembelajaran AIK yang dijelaskan di atas, kondisi Covid-19 dipandang sebuah situasi yang dapat menjadi penghalang tercapainya tujuan dan orientasi pembelajaran AIK sebagaimana di atas. Pandangan ini bukan berarti peneliti pesimis terhadap pencapaian tujuan pembelajaran, melainkan sebuah realita yang dihadapi berbagai lembaga pendidikan dalam kegiatan proses pembelajaran yang dilaksanakan dari rumah melalui pemanfaatan platform yang tersedia.

Situasi new normal pada awalnya diharapkan semua aspek kehidupan kembali kepada kondisi sebelum Covid-19 (Sparrow et al., 2020). Namun dalam perkembangan selanjutnya kondisi new normal tidak jauh berbeda dengan kondisi Covid-19, dimana kegiatan kehidupan manusia seperti perekonomian, perdagangan, kegiatan ibadah dan pendidikan berlangsung sebagaimana kondisi Covid-19.

Pandemi Covid-19 sampai saat ini masih terus menyebar belum dapat dipastikan sampai kapan pandemi ini akan berakhir. Kebijakan yang diambil untuk mengantisipasi penyebaran virus agar Covid-19 tidak meluas belum menunjukkan hasil yang baik. Kenyataan belum berakhirnya Covid-19 pada era new normal mengharuskan semua sekolah dan madrasah di bawah naungan Muhammadiyah membuat langkah-langkah kebijakan untuk melaksanakan kegiatan belajar dari rumah (BDR) (Mursal et al., 2021). Walaupun belajar dari rumah, pembelajaran harus mengacu pada arah tujuan pembelajaran yang ada, pencapaian tujuan pembelajaran pada masa Covid-19 setidaknya tidak mengalami penurunan yang drastis dibanding situasi normal(Engzell et al., 2021).

Untuk mencapai tujuan pembelajaran pada masa new normal guru tidak bisa hanya mengandalkan model pembelajaran sebagaimana situasi Covid-19 yakni hanya memanfaatkan platform seperti ruang guru, google meeting, email, whatsApp group, zoom, edmodo atau platform lainnya (Gunawan et al., 2020). Begitu juga dalam aspek media, pendidik tidak dapat hanya mengandalka media pembelajaran yang biasa digunakan pada pembelajaran dalam situasi normal, melainkan guru mesti memiliki inovasi dalam memilih media yang tepat. Hal ini dikarenakan bahwa pemanfaatan media yang tepat dalam pembelajaran pada masa Covid-19 merupakan bagian dari langkah untuk menjaga kualitas pembelajara (Barnansyah, 2021)

Berbagai macam upaya dalam meningkatkan mutu pembelajaran perlu dilakukan supaya peserta pendidik mendapatkan bimbingan belajar secara maksimal. Penerapan model pembelajaranpun mutlak dilakukan oleh seorang pendidik baik dari penggunaan strategi dan model pembelajaran, sampai pada penekanan yang dapat merubah pola pikir (mindset). Seperti peran guru yang dulunya hanya sebagai transfer pengetahuan saja menjadi fasilitator (Keiler, 2018), dari peran guru yang hanya menjadi sumber belajar menjadi kawan belajar, dari belajar yang berpatokan pada kurikulum berubah menjadi belajar yang dipusatkan pada peserta didik, dari belajar yang tersusun sesuai 
jadwal menjadi belajar yang fleksibel dan terbuka sesuai kebutuhan (Otaki et al., 2021; Naidu, 2017).

Begitu juga, peranan seorang pendidik sekaligus sebagai praktisi pendidikan dalam meningkatkan mutu pembelajaran, hendaknya dalam meningkatkan pembelajarannya terus melakukan perbaikan-perbaikan baik yang menitik beratkan pada strategi, model maupun penggunaan media baik media audio, visual dan audiovisual dalam pembelajarannya (Munir, 2009). Sejalan dengan perkembangan teknologi informasi yang telah masuk dalam dunia pendidikan, maka berbagai model dan strategi pembelajaran telah diciptakan melalui pemanfaatan teknologi informasi menjadi lebih menarik (Ritonga et al., 2016).

Model pembelajaran yang diterapkan di masa depan diarahkan untuk pola pembelajaran yang memafaatkan teknologi informasi, orang bisa belajar kapanpun, tidak lagi hanya di ruang formal saja, tapi bisa di pustaka dan diberbagai tempat lainya, belajar tidak berpatokan dengan jadwal, belajar dengan pakar kompeten, belajarpun bisa melalui sarana penunjang lainnya.

Perkembangan teknologi sangat cepat dan semakin canggih terutama berkaitan dengan teknologi komunikasi dimulai dari adanya handphone yang fiturnya semakin beragam dan atraktif mudah untuk digunakan dalam berbagai hal, seperti informasi terkini yang terjadi dibelahan bumi bisa diakses dalam hitungan detik, aplikasi sosial media yang lengkap sampai chatting via online dan lainnya.

Dalam perkembangan teknologi di dunia pendidikan juga mengalami pergeseran, dimana internet dalam pembelajaran menjadi sumber literasi yang luas untuk menambah wawasan belajar. Internet mempunyai manfaat dan potensi yang besar apabila dapat dioptimalkan dengan sebaik-baiknya dalam rangka menambah wawasan dan ilmu pengetahuan (Apuke \& Iyendo, 2018). Internet merupakan sarana komunikasi murah dan cepat melalui ragam aplikasi media sosial seperti instagram, facebook, twitter, WhatsApp, dan sebagainya (Sham et al., 2017), melalui aplikasi-aplikasi yang menarik inilah dapat menyita perhatian anak-anak usia sekolah, seakan keberadaan handphone menjadi sesuatu yang wajib dimiliki oleh mereka.

Oleh karena itu, guru harus dapat memanfaatkan perkembangan teknologi handphone ini dalam mengimplementasikan pembelajaran melalui model daring yang digabungkan dengan luring (blended learning). Gabungan antara online dan offline penting untuk dilakukan mengingat pembelajaran yang dilaksanakan hanya mengandalkan online sebagaimana pada masa Covid-19 hasilnya kurang maksimal. Pembelajaran secara online atau e-learning yang dapat diakses oleh peserta didik dimanapun dan kapanpun melalui perangkat komputer, laptop, smartphone/ handphone masing-masing siswa, diantara keunggulan dari memanfaatkan media online atau $e$ learning antara lain: fleksibilitas dilihat dari segi tempat dan waktu yang digunakan, dalam menggunaan media online tidak berpatokan pada waktu efektif sekolah, fleksibilitas dilihat dari segi fasilitas yang digunakan serta lingkungan belajar (Sadeghi, 2019), disebabkan peserta didik sangat mudah mengakses fitur-fitur e-learning melalui

Tarsupon. (2021). Learning Al-Islam and Kemuhammadiyahan by Using Blended Learning in the New Normal at MTs Muhammadiyah Lubuk Jambi. Ruhama :Islamic Education Journal, Vol. 4, (No. 2), pp. 145-158 DOI: https://doi.org/10.31869/ruhama.v4i2845 
fasilitas yang beragam, suasana menjadi rilek (Szadziewska \& Kujawski, 2017), hal ini disebabkan siswa bebas serta mampu dalam mencoba latihan secara online, waktu pembelajarannya dapat diperbarui.

Berdasarkan pandangan di atas, pembelajaran pada masa new normal membutuhkan kreativitas guru guna mensukseskan proses pembelajaran. Inovasi itu terkait dengan penggunaan media serta model pembelajaran yang tidak hanya mengandalkan teknologi informasi dan komunikasi dan tidak pula statis sebagaimana pembelajaran sebelum adanya masa Covid-19, namun lebih mengarah pada penggabungan dua model baik yang online maupun offline.

Pembelajaran dengan sistem blended learning telah banyak digunakan oleh para guru sebagai upaya untuk menjaga dan meningkatkan kualitas pendidikan. Kesimpulan yang didapatkan Dziuban dan kawan-kawan terkait dengan penggunaan blended learning ialah bahwa pembelajaran yang dilaksanaka secara tatap muka lebih mendominasi terhadap perkembangan sosial peserta didik, hal ini disebabkan karena pembelajaran yang dilaksanakan secara online peserta didik merasakan lingkungan yang sepi, kurang interaktif (Dziuban et al., 2018).

Berdasarkan uraian di atas, penelitian ini bertujuan untuk mengungkapkan bagaimana implementasi blended learning dalam pembelajaran AIK pada masa new normal di MTs Muhammadiyah Lubuk Jambi. Secara khusus fokus penelitian diarahkan pada: pertama, perencanaan pembelajaran AIK dengan model blended learning, kedua, pelaksanaan pembelajaran AIK dengan menggunakan model blended learning, ketiga hasil pembelajaran AIK dengan menggunakan blended learning.

\section{METHOD}

Gambaran objek yang diamati dalam penelitian ini yaitu tentang studi lapangan bagaimana gambaran pengimplementasian blended learning dalam pembelajaran AIK dengan setting penelitian di lingkungan MTs Muhammadiyah Lubuk Jambi, gambaran kondisi sekolah yang heterogen. Dalam menggali informasi yang mendalam terkait kondisi lingkungan sekolah, peneliti melakukan wawancara kepada kepala sekolah atau wakil kepala sebagai partisipan, kepada guru Al-Islam, Kemuhammadiyahan untuk mendapatkan data yang terperinci berkaitan dengan kondisi peserta didik, metode pembelajaran yang digunakan serta hal yang berkaitan dengan mata pelajaran Al-Islam, Kemuhammadiyahan, sebagai obyek yang berkaitan dengan pengimplementasian blended learning peneliti juga mengerjakan pengamatan serta interview pada siswa kelas VIII ${ }^{2}$ dan kelas IX $^{3}$.

Dalam penelitian ini, peneliti mengharapkan adanya deskripsi rangkaian alur kegiatan pembelajaran sesuai fakta lapangan pada proses pelaksanaan blended learning pada materi Al-Islam, Kemuhammadiyahan pada masa new normal, sebagai bahan kajian dalam menemukan kekurangan dan kelemahan pembelajaran dimaksud, sebagai bahan untuk menentukan proses penyempurnaan. Oleh sebab itu yang diamati melalui dasar pendekatannya, karakter penelitian ini adalah penelitian yang bersifat kualitatif. 
Pengertian penelitian kualitatif (qualitative research) yaitu penelitian yang ditujuannya menggambarkan, merinci peristiwa, gejala, hubungan sosial, sikap, persepsi, kepercayaan, dan pemikiran orang baik secara pribadi ataupun secara berkelompok (Ospina, 2004).

Penggunaan metode dalam penelitian ini adalah cara kerja model deskriptif kualitatif dengan bentuk studi lapangan. Tujuan metode ini untuk mendapatkan gambaran secara komprehensif dan terperinci tentang fenomena dan kejadian tertentu pada suatu subyek dan obyek yang mempunyai ciri khusus untuk mendapatkan informasi yang banyak dan detil kemudian digambarkan secara naratif dan utuh (Aspers $\&$ Corte, 2019).

Dalam penelitian ini, pengumpulan data yang dilakukan menggunakan setting alamaiah yaitu kondisi lingkungan sekolah. Sebagai pusat data primer yaitu peneliti itu sendiri yang langsung turun ke lapangan sebagai lokasi penelitian, yaitu MTs Muhammadiyah Lubuk Jambi. Sebagai data pendukung dalam teknik pengumpulan menggunakan data antara lain; melakuakan observasi para partisipan, dimana peneliti langsung kelapangan mengamati pembelajaran oleh guru AIK di sekolah untuk merasakan dan mengamati secara langsung, melakuakan wawancara mendetail kepada kepala sekolah sebagai orang yang diberikan wewenang, guru AIK terkait, serta siswa sebagai sumber observant; mengambil informasi melalui dokumentasi, mengamati dokumen yang berkaitan dengan kondisi sekolah, perkembangan siswa, foto- foto, dan lain sebagainya.

Peneliti menjadi instrumen atau alat penelitian sumber utama dalam penelitian kualitatif. Oleh karenanya, peneliti harus "divalidasi” untuk mengukur sejauh mana kesiapan peneliti kualitatif turun langsung melihat objek lapangan. Maka dari itu peneliti dalam penelitian kualitatif disebut juga, "the researcher is the key instrument" (Pezalla et al., 2012). Pendekatan penelitian ini menggunakan model pendekatan kualitatif dimana mengharuskan peneliti untuk secara langsung turun kelapangan dalam rangka menggali informasi sebanyak-banyaknya dan sedalam-dalamnya untuk mendapatkan gambaran secara naratif dan utuh tentang fenomena yang terjadi, sebagai data primer atau data utama dalam alat pengumpul atau intrumen penelitian ini adalah peneliti itu sendiri. Sementara sebagai data sekunder atau data pendukung, peneliti mendapatkan melalui instrumen data dengan menggunakan pedoman observasi, pedoman wawancara, serta pedoman dokumentasi.

Prosedur penelitian kualitatif terdiri dari berbagai macam variasi tahapan penelitian, tetapi secara umum arah penelitian pada tahapan-tahapan prosedur yang harus dilakukan oleh peneliti terbagi jadi 3 prosedur penelitian, yaitu: pertama tahap persiapan, terdiri dari, pengurusan surat perijinan kepada pihak MTs Muhammadiyah Lubuk Jambi, membuat list lembaran pendukung diantaranya pedoman observasi, proses wawancara dan observasi dokumentasi, melakukan studi bacaan, memetakan kondisi sosial lingkungan sekolah, melakukan wawancara pra penelitian; kedua, tahapan

Tarsupon. (2021). Learning Al-Islam and Kemuhammadiyahan by Using Blended Learning in the New Normal at MTs Muhammadiyah Lubuk Jambi. Ruhama :Islamic Education Journal, Vol. 4, (No. 2), pp. 145-158 DOI: https://doi.org/10.31869/ruhama.v4i2845 
pelaksanaan penelitian, diantaranya pelaksanaan pembelajaran blended learning dan melakukan wawancara, dan tahap ketiga, diantaranya pengolahan dan analisis data.

Adapun model interaksi digunakan untuk teknik analisis data sebagaimana dikemukakan Miles \& Huberman. Menurut mereka ada empat tahapan dalam teknik analisis data model interaktif antara lain: Tahap pertama yaitu pengumpulan data, tahap kedua yaitu reduksi data, tahap ketiga adalah yaitu display data, dan tahap keempat yaitu penarikan kesimpulan atau tahap verifikasi (Miles \& Huberman, 1994).

\section{RESULTS\&DISCUSSION}

\section{Penerapan Dalam Model Blended Learning Pada Pembelajaran AIK}

Penerapan model yang dilakukan pada pembelajaran blended learning di MTs pada awalnya bisa dibilang berlangsung baik karena guru AIK cukup memahami sistem pembelajaran menggunakan Whatsapp ini yang dalam online learning dimana hal ini bagian dari faktor utama dari suatu komponen pada pembelajaran blended. Ketika diterapkan pada sistem pembelajaran model ini peneliti mendapat gambaran pada awalnya siswa juga merasa senang pembelajaran AIK. Keakraban siswa dan guru dalam hal ini terjalin dengan lancar sebagaimana komunikasi yang terjadi selama berlangsungnya siswa merasa nyaman belajar menggunakan kelas daring ini sehingga proses belajar transfer pengetahuan tetap berjalan dari guru diturunkan ke siswa mencapai keberhasilan yang diharapkan dengan kesuksesan, walaupun tidak begitu efektif pada hasilnya.

Menurut peneliti model pembelajaran daring ini dirasa memang memiliki pengaruh signifikan dan efektif dalam meningkatkan hasil belajar apalagi jika selaras dikombinasikan pelaksanaannya dengan ditambahkan dengan model klasikal tatap muka terbatas.

Dikembangkannya model blended learning ini tentunya mempunyai tujuan untuk menghasilkan pembelajaran yang terbaik dalam menggabungkan model terbaik saat ini yaitu berupa pembelajaran yang sudah umum dilakukan dengan tatap muka di kelas dengan menggabungkan model terbaik melalui pembelajaran online saat ini sehingga menumbuhkan kesadaran pembelajaran mandiri yang dilakukan secara aktif oleh siswa yang akan berdampak pada berkurangnya durasi waktu jam tatap muka yang dilakukan di dalam di kelas (Oweis, 2018). Penerapan pembelajaran yang dilaksanakan pada situasi pandemi saat ini di MTs Muhammadiyah Lubuk Jambi, bahwa ini menjadi salah satu jenis pembelajaran yang diharapkan dapat menimbulkan rasa nyaman dan senang baik bagi guru maupun siswa, dengan jenis variasi gabungan yang kadang dilakukan secara klasikal dan pada kesempatan yang lain dilakukan secara daring ini.

Mengacu pada konsep teori yang ada dapat menggambarkan fungsi dari blended learning ini digunakan untuk menutupi celah kekurangan yang terjadi pada proses belajar tatap muka murni serta prose belajar e-learning murni (Ma \& Lee, 2021). Beberapa manfaat yang dapat digunakan pada model gabungan ini diantaranya siswa tidak saja berpatokan hanya pada satu buku saja akan tetapi juga dapat menambah rujukan pengetahuan dari memanfaatkan model e-learning dengan memanfaatkan aplikasi whatsapp dimana setiap siswa dapat membaca, berkomentar, bertanya serta mengunduh materi online yang telah dikirimkan oleh guru pada kelas berbasis virtual tersebut, ini diantara salah satu keunggulan belajar melalui aplikasi yang ada di 
smartphone dimana materi bisa dibaca, disimpan ataupun dicetak, sesuai keinginan kita, seperti diketahui bersama bahwa perubahan zaman dapat mengubah cara pandang dan belajar siswa, perkembangan teknologi pada zaman ini dapat merubah paradigma guru dalam mengajar dan juga paradigma siswa dalam belajar mereka dapat berselancar memilih materi yang ingin dibaca serta pelajaran yang diperlukan lainnya, diantara kelebihan berikutnya siswa bisa saling berdiskusi lewat room chat walaupun jaraknya tidak berdekatan, kemudian saling berkirim dokumen file materi, serta tidak terikat dengan jarak dan waktu artinya siswa besas untuk mengakses dimana saja dan kapan saja.

Setiap ada kelebihan tentunya juga suatu model pembelajaran akan mempunyai kekurangan yang selalu menyertai, begitupun setiap kekurangan pasti akan dibarengi kelebihannya itu sebabnya begitu sulitnya menemukan sesuatu yang sempurna (Bervell \& Umar, 2020), dalam hal ini media yang diperlukan sebenarnya memiliki variasi yang sangat beragam macamnya sehingga membutuhkan perangkat kesiapan dari dukungan sarana serta prasarana yang lengkap di sekolah, sesuai kondisi lapangan yang peneliti lihat sebenarnya untuk persiapan dan kelengkapan sarana serta prasarana sudah dikatakan mencukupi dan lengkap hanya saja masih ada bagian komponen yang belum dimaksimalkan fungsinya sebagaimana fungsinya terutama yang berkaitan dengan faktor penunjang utama pembelajaran model blended yaitunya tersedianya jaringan internet yang optimal dan stabil serta yang bisa dimanfaatkan untuk menunjang pembelajaran model tersebut, apabila dalam pembelajaran ini koneksi jaringan internet kurang maksimal akan berakibat pada kesulitan dalam penerapan metode ini, seperti kondisi jaringan di MTs Muhammadiyah Lubuk Jambi sudah bisa dikatakan stabil jika menggunakan Jaringan Handphone namun cukup merepotkan dalam menyambungkan kedalam jaringan Wifi yang terdapat disekolah karena sering bermasalah dan mati kalaupun dapat terhubung dengan jaringan disekolah tapi kadang jaringannya lelet sehingga susah untuk digunakan guru secara bersamaan waktunya.

Kelemahan berikutnya yaitu berkaitan dengan ketersediaan fasilitas yang dipunyai oleh masing-masing siswa terutama ketersediaan Smartphone, kemudian paket data internet, mengingat secara ekonomi orang tua mereka berbeda-beda sehingga tidak semua siswa memiliki Smartphone ataupun paket data yang selalu tersedia (Nasution et al., 2019). Dalam mengamati penggunaan model blended yang diterapkan sekolah pada situasi pandemi ini tentunya guru telah merancang beberapa alternatif penyampaian materi model blended apabila dilapangan terjadi kegagalan koneksi internet atau mengalami pelambatan jaringan sehingga tidak mungkin pembelajaran daring berjalan maksimal maka jalan keluar yang diberikan guru untuk mengatasi masalah ini hanya akan mengirimkan tugas saja untuk dikerjakan yang nantinya tugas ini akan dikumpulkan pada minggu berikutnya.

Selaras dengan pembelajaran yang diterapkan di MTs Muhammadiyah Lubuk Jambi motivasi belajar siswa dalam kegiatan pembelajaran blended tentunya akan berbeda dari segi motivasi dan semangatnya antara pembelajaran model tatap muka saja ataupun hanya e-learning saja sesuai dengan apa hasil penelitian yang dilakukan oleh oleh (Hamad, 2015), dimana dia menyimpulkan bahwa hasil dari penelitian yang dilakukannya terdapat perbedaan yang jauh antara motivasi yang dimiliki siswa dalam proses pembelajaran menggunakan blended learning dengan menggunakan metode konvensional. Hal ini juga hampir sama dengan apa yang peneliti temukan di MTs Muhammadiyah Lubuk Jambi dimana mereka lebih menyukai model pembelajaran

Tarsupon. (2021). Learning Al-Islam and Kemuhammadiyahan by Using Blended Learning in the New Normal at MTs Muhammadiyah Lubuk Jambi. Ruhama :Islamic Education Journal, Vol. 4, (No. 2), pp. 145-158 DOI: https://doi.org/10.31869/ruhama.v4i2845 
yang dilakukan dengan cara blended dibandingkan dengan hanya melaksanakan pembelajaran model konvensional atau tatap muka,peneliti dalam hal ini melihat tidak semua kelas, dan yang menerapkan hanya di beberapa kelas.

Proses pembelajaran berbasis blended learning ini dapat merubah pola pikir tentang pembelajaran yaitu dari awalnya pembelajaran hanya berpusat ke guru menuju pola pikir sebaliknya yaitu berpusat pada siswa. Sebagaimana dengan apa yang dijabarkan dari hasil penelitian yang dilakukan oleh Kintu dan kawan-kawan (Kintu et al., 2017) dalam kesimpulan penelitian tersebut bisa menambah keaktifan, menumbuhkan sikap kemandirian belajar, serta meningkatkan hasil belajar siswa.

Hal yang hampir serupa juga peneliti temukan ketika melakukan penelitian di MTs Muhammadiyah Lubuk Jambi bahwa merangkum dari semua hasil wawancara kepada guru sepakat bahwa model pembelajaran yang diterapkan ini juga bisa meningkatkan hasil dari belajar siswa. Kemudian juga dapat melatih siswa untuk belajar mandiri.

Pembelajaran secara blended tidak sepenuhnya berpengaruh pada bagian rencana pembelajaran yang dibuat oleh guru, tahapan proses pembelajaran tidak banyak mengalami perubahan tetap mengacu pada rencana yang telah dibuat memang ada sedikit perubahan terkait pengimplementasiannya telah diterapkan model bauran yang memadukan e-learning dengan face-to-face.

Penyesuaian rencana pembelajaran guru telah disusun mengacu pada silabus yang digunakan di MTs Muhammadiyah Lubuk Jambi yaitu silabus kurikulum 2013 sehingga apa yang saja kegiatan belajar guru harus mengikuti panduan yang ada pada kurikulum tersebut, demikian juga dalam penyususnan komponen pelengkap lainnya terutama prota, promes, dan lainnya tetap berpedoman pada kurikulum.

Dalam pembelajaran model ini sudah menjadi kewajiban guru untuk memegang tanggung jawab pada tingkat keberhasilan siswa dalam belajar, melihat benar hasilnya siswa akan menikmati proses pembelajaran terasa nyaman, senang dan gembira sehingga akan meningkatkan prestasi belajar dibanding dengan yang telah berlalu. Hal ini sesuai hasil dari wawancara yang dilakukan penulis pada informan utama yang bertanggung jawab dalam meningkatkan hasil belajar siswa.

Penerapan model Blended Learning telah mendapat tanggapan yang positif bila hasilnya dapat meningkatkan hasil belajar serta bisa memahami pelajaran. Ia menganjurkan penerapan Blended Learning dalam pembelajaran, walaupun demikian masih banyak guru yang belum siap menerapkan model ini seperti kebanyakan guru menganggap model yang digunakan ini membutuhkan pekerjaan yang banyak karena harus mengirim file materi berbagai format dan sebagainya, walaupun demikian mengingat kegunaannya sangat beragam juga dapat memudahkan pekerjaan guru, seperti ketika guru akan menjelaskan atau memberi materi tambahan lewat Whatsapp kemudian siswa dengan waktu yang fleksibel bebas ketika akan mengunduhnya untuk dipelajari secara mandiri atau berkelompok serta segudang manfaat lainya yang bisa diambil kebaikannya.

Masalah lainnya yang sama-sama kita tahu adalah terpenuhinya internet yang stabil, dan masalah ini merupakan hal yang perlu jadi perhatian utama karena hai ini menjadi kunci dari keberhasilan pembelajaran model ini dengan itu maka pihak sekolah harus mncari solusi terbaik agar kuota internet siswa terpenuhi (Sartika et al., 2021). Selain dari itu kuota internet guru juga dibayarkan oleh sekolah.

Usaha semacam ini telah dipraktekkan oleh guru AIK dalam pelaksanaan pembelajaran terbilang sudah bagus dan mengacu pada tahapan yang ada, tindakan 
semacam ini sangat layak untuk kegiatan selanjutnya sebab bukan hanya memegang pelajaran AIK secara khusus akan tetapi juga paham akan penerapan perkembangan arus modern maka dengan penguasaan teknologi komunikasi dan informasi yang dimiliki ini dapat membantu semua kegiatan belajar menjadi mudah.

Pembelajaran guru AIK saat dilakukan pengamat sedang terjadi pada jam ke 3 pembelajaran AIK, saat jam ketiga sedang berlangsung didalam kelas secara konvensional dan pada saat tersebut materi yang dibahas terkait inti dari pokok bahasan atau materi esensial mengingat waktu belajar ketika tatap muka terbatas sangat singkat sehingga materi yang disampaikan harus yang penting-penting saja. Sesudah menjelaskan materi guru melanjutkan via belajar daring menggunakan Whatsapp sebagai penegasan materi dan pemberian tugas dirumah.

\section{Kendala Dalam Pembelajaran Model Blended Learning}

Hasil dari penelitian yang ditemukan peneliti melalui tahapan observasi dan wawancara yang dilakukan didapatlah informasi lewat informan utama dan juga melalui informan pendukung, maka dapat disimpulkan permasalahan yang paling urgen dan mendesak terdapat pada koneksi jaringan internet yang tidak memadai serta perangkat pendukung pembelajaran yang digunakan masih kurang memadai, permasalahn ini jadi topik yang penting serta urgen untuk dibahas jika berkaitan dengan model belajar blended learning ini disebabkan dalam penerapan model daring luring ini sanagt tergantung pada ketersediaan koneksi jaringan internet stabil dan lancar yang akan berdampak langsung pada proses belajar online menjadi efektif dan efesien tentunya.

Fokus utama yang menjadi kendala pada bagian e-learning ini yaitu masih berkutat dengan terhambatnya koneksi data internet jaringan wifi sekolah atau paketan data yang berakibat langsung pada terhambatnya proses belajar, sementara itu hasil dari observasi yang dilakukan peneliti ketika mengamati pembelajaran secara langsung dikelas dengan sistem tatap muka terbatas tidak terlihat hambatan yang serius, paling hanya ada beberapa siswa yang tidak serius dan tidak fokus pada materi yang disampaikan guru ketika mengajar, semua hal itubisa diatasi guru disebabkan penyediaan sarana pembelajaran klasikal dan prasarana yang ada sudah cukup memadai guna menunjang keberhasilan belajar siswa, proporsi alokasi waktu belajar konvensional seharusnya lebih banyak dan seharusnya alokasi waktu belajar online seharusnya lebih sedikit mengingat belajar online hanya sebagai penyempurna dari pembelajaran dikelas.

Melihat kondisi lapangan peneliti mendapatkan gambaran sudah cukup memadainya fasilitas yang ada hanya beberapa yang perlu difasilitas yang kurang terutama pada bagiana jaringan internet wifi disekolah yang masih mengalami kendala masih kurang stabil sewaktu-waktu dan paket internet yang habis walaupun secara khusus sudah terkoneksi.

Berdasarkan pemaparan yang ada baik data yang tersaji dari observasi lapangan langsung maupun lewat wawancara maka peneliti dapat menyimpulkan permasalahan yang timbul dari penerapan blended learning bahwa pada tingkatan sekolah dasar sebenarnya kebutuhan akan koneksi jaringan internet belum terlalu urgen akan tetapi dengan adanya kebijakan yang ada dari pemerintah melalui pihak sekolah untuk menerapkan belajar daring luring maka ketersediaan koneksi internet yang stabil menjadi penting disediakan oleh pihak madrasah walaupun untuk meningkatkan kapasitas kestabilan jaringan ini membutuhkan biaya yang sangat besar apalagi ini

Tarsupon. (2021). Learning Al-Islam and Kemuhammadiyahan by Using Blended Learning in the New Normal at MTs Muhammadiyah Lubuk Jambi. Ruhama :Islamic Education Journal, Vol. 4, (No. 2), pp. 145-158 DOI: https://doi.org/10.31869/ruhama.v4i2845 
sekolah swasta yang tentunya menjadi beban dan kendala tersendiri dalam menyiapkan fasilitas yang memadai ini.

\section{Upaya Dalam Mengatasi Kendala Model Blended Learning}

Berdasar fakta dilapanganbahwa data yang diperoleh, peneliti melihat secara komprehensif merangkum kemudian menyimpulkan dari apa yang ada dengan merincikan data melalui observasi yang telah dilakukan, kemudian wawancara terhadap informan dan juga melakukan studi dokumentasi yang ada berkenaan dengan berbagai upaya baik dari pihak sekolah, guru maupun dari siswa sendiri untuk mengatasi permasalah yang timbul akibat penerapan model blended learning dalam pembelajaran, beberapa siswa dalam wawancara langsung mengatakan pelaksanan pembelajaran memakai whatsapp pasti memerlukan paket data internet bisa juga menggunakan hotspot wifi sebagai sebagai alternatif jaringan. Penerapan model ini memang membutuhkan perhatian yang lebih mengingat pembelajaran online mempunyai kendala yang serius besar dalam penerapannya.

Untuk itu baik pihak sekolah memberikan beberapa alternatif terobosan sebagai upaya agar kendala dalam pembelajaran daring, dari pihak sekolah telah berupaya memperbaiki konektifitas wifi yang ada disekolah selain itu juga setiap guru diberikan dana untuk pembelian paket data untuk kelancaran proses pembelajaran daring kemudian untuk meringankan siswa pihak sekolah juga memberikan kartu paket internet dengan bekerjasama dengan jaringan XL dan juga dengan mengusulkan bantuan data internet dari Kementerian Agama.

Sementara itu dari sisi guru juga memberikan beberapa terobosan dalam pembelajaran agar siswa tidak merasa terbebani dengan memberikan waktu yang lebih fleksibel dalam pemberian tugas biasanya diberikan waktu satu minggu setiap mata pelajaran dan juga materi yang tidak terlalu banyak agar siswa tidak kesulitan dalam mengerjakan tugas.

Dari beberapa penuturan siswa ada sangat bervariasi dalam memberikan pandangan hasil dari wawancara dimana siswa lebih dominan pada pembelian paket data internet atau solusi lain yaitu meminta paket kepada teman untuk sekedar melihat materi yang diberikan, peneliti merasa untuk permasalahan paket data internet ini mungkin menjadi sesuatu yang dibutuhkan yang dianggap pokok bagi sebagian siswa hal ini mengingat mengisi paket kuota data internet jadi hal yang didahulukan jikalau habis, bukan hanya hal itu mereka juga menggunakan kuota internet ini digunakan bersosial media baik facebook, instagram, whatsapp yang mereka punya, oleh karena itu mengingat pembelajaran yang membutuhkan internet ini peneliti berharap dilakukan secara optimal agar hasil yang didapatkan sesuai dengan keinginan.

Pada dasarnya pembelajaran model daring luring yang dilakukan sudah mencapai berbagai komponen dan unsur. Unsur-unsur itu cakupannya meliputi: Pembelajaran tatap muka (konvensional); unsur Pembelajaran daring atau Online learning; serta unsur belajar mandiri. Kenyataan yang ada, Blended learning sudah ada semenjak berkembangnya teknologi yang pemanfaatan teknologi internet ini diterapkan dalam dunia pendidikan. Apalagi dimasa pandemi covid-19 ini model pembelajaran blended learning semakin populer diterapkan dalam sistem belajar dari rumah dengan memanfaatkan jaringan internet yang menjanjikan berbagai kemudahan.

Akan tetapi pesatnya teknologi belum bisa mengajarkan dan merubah sikap, mental dan akhlak, serta pengembangan keahlian. Melihat kenyataan ini yang masuk kedalam wilayah penilaian sikap. Maka kekurangan dapat ditutupi dengan belajar 
klasikal tatap muka secara langsung (face to face) yang sangat dibutuhkan. Maka bisa di ketahui bersama ketiga unsur yang ada dalam model blended learning itu sifatnya saling melengkapi, dimana penerapan sistem online jangan difokuskan oleh guru saja akan tetapi juga wajib menerapkan sistem klasikal tatap muka langsung manfaatnya untuk mengarahkan maksud yang belum dipahami ketika belajar online serta pesan moral yang terkandung dalam materi. Begitu juga, belajar mandiri dibutuhkan untuk mempertajam daya pikir serta menumbuhkan sifat kemandirian siswa.

Berdasarkan teori yang ada semestinya blended learning dapat menutupi dari kelemahan yang terdapat di sistem klasikal tatap muka ataupun sistem online, peneliti mendapatkan berbagai keunggulan berbagai ragam banyaknya dari penerapan model blended learning tersebut, satu diantaranya yaitu siswa bisa bertanya langsung atau berdiskusi dua arah tanpa rasa malu dan canggung baik didalam jam pelajaran maupun diluar jam mengajar dengan memanfaatkan aplikasi Whatsapp group masing-masing mata pelajaran sehingga guru juga dapat mengelola dengan baik pembelajaran, menambah dan menjelaskan materi, memberi tugas, umpan balik didalam aplikasi tersebut, sehingga pemanfaatan waktunya jadi lebih efektif dan efisien.

Penerapan pembelajaran blended learning, mengubah pradigma bahwa belajar bukan lagi terpaku pada guru akan tetapi siswa lah aktif sebagai pusat belajar. Peneliti juga sepakat dengan apa yang ditulis oleh Caner bahwa penerapan pembelajaran model blanded learning lebih professional dalam memenuhi kebutuhan belajar yang efektif, efisien dan mempunyai minat belajar maksimal (Caner, 2012). Sesuai dengan fakta melalui hasil observasi lapangan dan juga saat dilangsungkanya wawancara yang mana peneliti mendapatkan berbagai informasi dari guru AIK, wakil kepala bidang ISMUBA, serta partisipan dari sejumlah siswa sebenarnya model belajar ini dapat menambah rasa antusias serta semangat belajar siswa, dengan hilangnya rasa jenuh, kebosanan saat belajar, malahan ada siswa berpendapat bahwa belajar saat model blended learning dapat membantu suasana saat belajar jadi lebih dinamis, dikarenakan mereka dapat belajar mandiri dan menjadi lebih aktif.

Akan tetapi selain manfaat yang ada juga kekurangan yang peneliti temui saat pelaksanaan model pembelajaran blended learning antara lain: paket internet yang terbatas sehingga berpengaruh pada anak-anak dalam mengakses Whatsapp di rumah, maka alternatif solusinya bisa dengan menggunakan jaringan Wifi yang ada disekitar rumah siswa.

\section{CONCLUSIONS}

Berdasarkan hasil melalui penelitian yang bersifat kualitatif dengan menggunakan teknik observasi, wawancara serta dokumentasi yang dilaksanakan di MTs Muhammadiyah Lubuk Jambi, tentang Implementasi Blended Learningdalam pembelajaran AIK pada masa Pandemi Covid-19 dapat ditarik kesimpulan Implementasi Blended Learning pada pembelajaran AIK saat Pandemi Covid-19 menunjukkan bahwa guru AIK pada saat pembelajaran menggunakan aplikasi Whatsapp tersebut sesuai dengan kebijakan dari kepala sekolah yang berpedoman kepada peraturan menteri tentang pembelajaran jarak jauh di tengah Pandemi yaitu dengan diadakan proses pembelajaran secara daring. Pelaksanaan pembelajaran dengan menggunakan aplikasi ini dirasa sangat bermanfaat dalam pembelajaran daring AIK,

Tarsupon. (2021). Learning Al-Islam and Kemuhammadiyahan by Using Blended Learning in the New Normal at MTs Muhammadiyah Lubuk Jambi. Ruhama :Islamic Education Journal, Vol. 4, (No. 2), pp. 145-158 DOI: https://doi.org/10.31869/ruhama.v4i2845 
karena memberikan kemudahan dalam pelaksanaan pembelajaran yang tetap mengacu pada Rencana Pelaksanaan Pembelajaran.

Kendala yang dialami guru AIK dalam penerapan Blended Learning pada pembelajaran AIK masa Pandemi Covid-19 di MTs Muhammadiyah Lubuk Jambi secara umum adalah kurangnya komunikasi dengan siswa dalam pembelajaran daring hal ini lebih dipengaruhi oleh faktor sinyal tempat tinggal siswa,tidak adanya hp yang dimiliki oleh siswa dan permasalahan kuota internet. Upaya dari pihak sekolah serta guru dalam usaha mengatasi masalah dan kendala dalam penerapan Blended Learning pada pembelajaran AIK masa Pandemi Covid-19 di MTs Muhammadiyah Lubuk Jambi adalah kepada guru AIK disediakan jaringan Wifi dan bantuan dana untuk pembelian kuota internet, memberikan siswa kartu paket data dan bantuan internet dari instansi terkait, guru AIK memberi waktu yang fleksibel kepada siswa dalam pembelajaran dan memberikan materi yang mudah dipahami, memberikan tugas dan penguatan materi melalui aplikasi Whatsapp agar siswa dapat belajar mandiri di rumah.

\section{BIBILIOGRAPHY}

Apuke, O. D., \& Iyendo, T. O. (2018). University students' usage of the internet resources for research and learning: forms of access and perceptions of utility. Heliyon, 4(12), e01052. https://doi.org/10.1016/j.heliyon.2018.e01052

Arifin, S. (2015). Rekonstruksi Al-Islam Kemuhammadiyahan (AIK) Perguruan Tinggi Muhammadiyah Sebagai Praksis Pendidikan Nilai. EDUKASI: Jurnal Pendidikan Agama Dan Keagamaan, 13(2), 201-221.

Aspers, P., \& Corte, U. (2019). What is Qualitative in Qualitative Research. Qualitative Sociology, 42(2), 139-160. https://doi.org/10.1007/s11133-019-9413-7

Baidarus, Hamami, T., Suud, F. M., \& Rahmatullah, A. S. (2019). Al-Islam dan kemuhammadiyahan sebagai basis pendidikan karakter. AL-ASASIYYA: Journal Basic Of Education, 4(1), 71-91.

Barnansyah, R. M. (2021). Implementasi Media Pembelajaran dalam Keterampilan Mengajar bagi Mahasiswa dalam Mata Kuliah Media dan Teknologi Pembelajaran di Masa Pandemi Covid-19. Hayula: Indonesian Journal of Multidisciplinary Islamic Studies, 5(2), 171-206. https://doi.org/https://doi.org/10.21009/hayula.005.02.04

Bervell, B., \& Umar, I. N. (2020). Blended learning or face-to-face? Does Tutor anxiety prevent the adoption of Learning Management Systems for distance education in Ghana? Open Learning, 35(2), 159-177. https://doi.org/10.1080/02680513.2018.1548964

Caner, M. (2012). The definition of blended learning in higher education. Blended Learning Environments for Adults: Evaluations and Frameworks, April 2012, 1934. https://doi.org/10.4018/978-1-4666-0939-6.ch002 
Dziuban, C., Graham, C. R., Moskal, P. D., Norberg, A., \& Sicilia, N. (2018). Blended Learning: the new Normal and Emerging Technologies. International Journal of Educational Technology in Higher Education, 15(1), 1-16. https://doi.org/10.1186/s41239-017-0087-5

Engzell, P., Frey, A., \& Verhagen, M. D. (2021). Learning loss due to school closures during the COVID-19 pandemic. PNAS, 118(17), 1-7. https://doi.org/10.1073/pnas.2022376118/-/DCSupplemental.y

Gunawan, Suranti, N. M. Y., \& Fathoroni. (2020). Variations of Models and Learning Platforms for Prospective Teachers During the COVID-19 Pandemic Period. Indonesian Journal of Teacher Education, 1(2), 61-70.

Hamad, M. M. (2015). Blended learning outcome vs. traditional learning outcome. International Journal on Studies in English Language and Literature (IJSELL), 3(4), 75-78. https://www.researchgate.net/profile/Mona-Hamad4/publication/283209693_Blended_Learning_Outcome_vs_Traditional_Learning Outcome/links/562df90d08aef25a24432332/Blended-Learning-Outcome-vsTraditional-Learning-Outcome.pdf

Keiler, L. S. (2018). Teachers' roles and identities in student-centered classrooms. International Journal of STEM Education, 5(34), 1-20. https://doi.org/10.1186/s40594-018-0131-6

Kintu, M. J., Zhu, C., \& Kagambe, E. (2017). Blended learning effectiveness: the relationship between student characteristics, design features and outcomes. International Journal of Educational Technology in Higher Education, 14(1), 1-20. https://doi.org/10.1186/s41239-017-0043-4

Ma, L., \& Lee, C. S. (2021). Evaluating the effectiveness of blended learning using the ARCS model. Journal of Computer Assisted Learning, 37(5), 1397-1408. https://doi.org/10.1111/jcal.12579

Miles, M. B., \& Huberman, A. M. (1994). Qualitative Data Analysis. In Sage Publication (2nd ed.). Sage Publication.

Munir. (2009). Pembelajaran Jarak Jauh berbasis Teknologi Informasi dan Komunikasi (TIK). Alfabeta. www.cvalfabeta.com

Mursal, M., Ritonga, M., Sartika, F., Lahmi, A., Nurdianto, T., \& Alam, L. (2021). The contribution of Amil Zakat, Infaq and Shadaqah Muhammadiyah (LAZISMU) institutions in handling the impact of Covid-19. Journal of Sustainable Finance and Investment, O(0), 1-7. https://doi.org/10.1080/20430795.2021.1886550

Naidu, S. (2017). How flexible is flexible learning, who is to decide and what are its implications? Distance $\quad$ Education, 38(3), 269-272. https://doi.org/10.1080/01587919.2017.1371831

Nasution, N., Jalinus, N., \& Syahril. (2019). Buku Model Blended Learning (B. Simamora (ed.); 1st ed.). Unilak Press.

Ospina, S. (2004). Qualitative Research. Encyclopedia of Leadership, 26(2), 63-64. https://doi.org/10.21091/mppa.2011.2010

Tarsupon. (2021). Learning Al-Islam and Kemuhammadiyahan by Using Blended Learning in the New Normal at MTs Muhammadiyah Lubuk Jambi. Ruhama :Islamic Education Journal, Vol. 4, (No. 2), pp. 145-158 DOI: https://doi.org/10.31869/ruhama.v4i2845 
Otaki, F., Zaher, S., Plessis, S. Du, Lakhtakia, R., Zary, N., \& Inuwa, I. M. (2021). Introducing the 4Ps model of transitioning to distance learning: A convergent mixed methods study conducted during the COVID-19 pandemic. PLoS ONE, $16(7$ July), 1-20. https://doi.org/10.1371/journal.pone.0253662

Oweis, T. I. (2018). Effects of Using a Blended Learning Method on Students' Achievement and Motivation to Learn English in Jordan: A Pilot Case Study. Education Research International, 2018, 1-7. https://doi.org/10.1155/2018/7425924

Pezalla, A. E., Pettigrew, J., \& Miller-day, M. (2012). Researching the researcher-asinstrument: an exercise in interviewer self-reflexivity. Qualitative Research Methods, 12(2), 165-185. https://doi.org/10.1177/1487941111422107

Ritonga, M., Nazir, A., \& Wahyuni, S. (2016). Pembelajaran Bahasa Arab Berbasis Teknologi Informasi dan Komunikasi. Arabiyat: Jurnal Pendidikan Bahasa Arab Dan Kebahasaaraban, 3(1), 1-12. https://doi.org/http://dx.doi.org/10.15408/a.v3i1.2879

Sadeghi, M. (2019). A Shift from Classroom to Distance Learning: Advantages and Limitions. Internasional Journal of Reserach in Englissh (IJREE), 4(1), 80-88.

Sartika, F., Ritonga, M., Lahmi, A., Rasyid, A., \& Febriani, S. R. (2021). Online Learning in the Low Internet Area, Planning, Strategies and Problems Faced by Students During the Covid-19 Period (D. Oliva, S. A. Hassan, \& A. Mohamed (eds.); Artificial). Springer. https://doi.org/https://doi.org/10.1007/978-3-03069744-0

Sham, M., Ali, S., \& Kootbodien, A. (2017). The Effectiveness of WhatsApp as an Interpersonal Communication Medium among Abu Dhabi University Students. International Journal of Media, Journalism and Mass Communications, 3(1), 1119. https://doi.org/10.20431/2454-9479.0301002

Sparrow, R., Dartanto, T., \& Hartwig, R. (2020). Indonesia Under the New Normal: Challenges and the Way Ahead. Bulletin of Indonesian Economic Studies, 56(3), 269-299. https://doi.org/10.1080/00074918.2020.1854079

Szadziewska, A., \& Kujawski, J. (2017). Advantages and Disadvantages of the Blended-Learning Method Used in the Educational Process At the Faculty of Management At the University of Gdansk, in the Opinion of Undergraduate Students. ICERI2017 Proceedings, 1(March 2018), 3938-3946. https://doi.org/10.21125/iceri.2017.1051 